\title{
Parameter Measurement and Calibration in Discrete Element Simulation of Broken Sweet Potato Seedlings
}

\author{
${ }^{1,2}$ Guizhi Mu, ${ }^{1}$ Xieteng Qi, ${ }^{1,2}$ Wangzhi Zhang, ${ }^{1,2}$ Zhaoqin Lv, ${ }^{1,2}$ Tingting Zhang and ${ }^{1}$ Shuwen Wang \\ ${ }^{1}$ College of Mechanical and Electrical Engineering, Shandong Agricultural University, Tai'an 271018, China \\ ${ }^{2}$ Shandong Provincial Key Laboratory of Horticultural Machineries and Equipments, Tai'an 271018, China
}

\author{
Article history \\ Received: 25-03-2021 \\ Revised: $10-05-2021$ \\ Accepted: 19-05-2021 \\ Corresponding Author: \\ Zhaoqin Lv \\ College of Mechanical and \\ Electrical Engineering, \\ Shandong Agricultural \\ University, Tai'an 271018, \\ China \\ E-mail: 1zqsdau2020@163.com
}

\begin{abstract}
Given the lack of accurate parameter values in discrete element simulation of sweet potato seedling mechanized recovery, a direct measurement and virtual calibration method was used to study the Discrete Element Method (DEM) simulation parameters of broken sweet potato stems and leaves. The intrinsic parameters, collision recovery coefficient and static friction coefficient of broken seedlings were acquired by physical experiments. Different parameter combinations were designed for DEM simulation. The intrinsic parameters of sweet potato leaves and other unmeasurable DEM simulation parameters were determined by stacking angle optimization simulation. Plackett-Burman test shows that the static friction coefficients of stem-stem and stem-steel and the rolling friction coefficients of stem-stem and stem-leaf all significantly influence the accumulation angle. The parameters that significantly influence the stacking angle of broken seedlings were sent to steepest ascent test and Box-Behnken test. The average stacking angle of $40.51^{\circ}$ and the relative error of $0.972 \%$ indicate it feasible to calibrate DEM parameters by physical test and optimization simulation and the calibrated parameters can be used in DEM simulation of broken sweet potato stems and leaves.
\end{abstract}

Keywords: Sweet Potato Seedlings, Discrete Element Method, Accumulation Angle, Optimal Design, Calibration

\section{Introduction}

Sweet potato vines are excellent fresh feeds and silage and thus their mechanized recycling has economic and social benefits (Kakahy et al., 2014; Zhao and Gao, 2012; Guizhi et al., 2019). Research on the action mechanism of sweet potato vines and harvesting machinery based on the Discrete Element Method (DEM) provides a theoretical basis for machinery design and optimization. DEM simulation requires many parameters, including intrinsic parameters (e.g., density, shear modulus and Poisson's ratio of sweet potato seedlings) and contact parameters (e.g., collision recovery coefficients, rolling friction coefficients and static friction coefficients between seedling particles and between particles and machine) (Boac et al., 2009; Ucgul et al., 2014; Leblicq et al., 2016). How to determine these parameters is the premise of applying DEM to the research on mechanized recovery of sweet potato vines.

Much research has been conducted to obtain DEM simulation parameters, mainly including direct measurement and virtual calibration (Martin et al., 2003; Horabik and Molenda, 2016; Sweijen et al., 2020). Grima and Wypych (2011) changed a cylinder lifting device to the left and right separation method and calibrated particle discrete element simulation parameters using the improved collapse test. González-Montellano et al. (2012) used direct measurement method to study some parameters in discrete element simulation. Junxiao et al. (2015) simulated straw particle accumulation and mixing movement in the rotating drum and calibrated the discrete element parameters of straw particles by comparison with actual experiments. Santos et al. (2015) obtained the dynamic angle of acerola residue by rotating drum experiment and calibrated the parameters needed in the discrete element simulation based on response surface method. Lee and Park (2019) designed four simulation friction tests to measure the static and rolling friction coefficients between materials and containers.

At present, no scholar has studied the discrete element simulation parameters of sweet potato seedlings. The above studies indicate that the intrinsic 
parameters of materials can be acquired direct measurement, but directly measuring and obtaining accurate contact parameters is difficult. In this study, physical tests were conducted to obtain the intrinsic parameters of broken sweet potato seedling stems, collision recovery coefficient and the static friction coefficient range of seedling particles. The intrinsic parameters of sweet potato leaves and other unmeasurable discrete element simulation parameters were simulated. The parameters were calibrated by simulation of crushed seedling particle accumulation optimization design. Through the Plackett-Burman test, the steepest climbing test and the Box-Behnken optimization test, the basic contact parameters were calibrated. The simulation data were compared with the physical test data, which provides a reference for the measurement and calibration of discrete element simulation parameters of sweet potato seedlings.

\section{Materials and Methods}

\section{Measurement of Intrinsic Parameters of Crushed Sweet Potato Seedlings}

\section{Group Measurement}

The broken potato seedlings harvested by a sweet potato seedling recycling machine were classified mainly into broken leaves, short stems and impurities (e.g., dry leaves, weeds, soil blocks). Five groups of mixtures were randomly selected and the average proportions of leaves, stems and impurities were 36.94, 59.2 and 3.85\% (very low), respectively. Clearly, seedling leaves and stems were the main particle components used in discrete element simulation. In fact, leaves and short stems were taken as the research objects.

Five samples of crushed sweet potato seedlings were randomly selected after removing impurities. Then leaf areas were measured and calculated using graph paper and the length and diameter of stems were detected using vernier calipers. The coefficients of variation in the measurements of sweet potato leaf area and stem length are larger than 15. The S-W tests show neither the measured leaf areas nor stem lengths satisfy normal distribution. To simplify the modeling, further classification and counting were adopted. The leaves were divided by area into two types: Broken leaves (area $>2 \mathrm{~cm} 2$ ) and finelyshredded leaves (area $<2 \mathrm{~cm} 2$ ). According to statistics, the average areas of broken leaves and finely-shredded leaves are 2.40 and $1.5 \mathrm{~cm}^{2}$, respectively and the coefficients of variation are 6.13 and $4.35 \%$, respectively. The stems were divided by length into long stems (length $>20 \mathrm{~mm}$ ) and short stems (length $<20 \mathrm{~mm}$ ). The average length and diameter of the long stems are 35.73 and $6.7 \mathrm{~mm}$, respectively and the coefficients of variation are 10.06 and $6.77 \%$, respectively. The average length and diameter of the short stems are 14.56 and $4.56 \mathrm{~mm}$, respectively and the coefficients of variation are 8.35 and $3.72 \%$, respectively. The statistical results of mass proportion of each component are shown in Table 1.

\section{Density Measurement}

The true density of particles is an important parameter of discrete element simulation. The densities of sweet potato stems and leaves were measured by the overflow equal volume method. Firstly, 50 stems each in length of $20 \mathrm{~mm}$ and 50 leaves were randomly selected and every 10 stems and every 10 leaves were bundled together with filaments. Then the stem or leaf quality was measured and the volumes were measured by the immersion method (Fig. 1). Water will overflow after putting the stems in a measuring cup full of pure water. Since the density of fresh sweet potato stems is less than that of water, the top was covered with a flat plate to ensure that all the stems can penetrate water. After the measuring cup was removed, the quality of the overflowing water was measured and the volume of water was calculated, which is the volume of the stems. The average density of sweet potato stems measured from five groups is $987.91 \mathrm{~kg} / \mathrm{m}^{3}$ and the coefficient of variation is $3.34 \%$. The density of sweet potato leaves measured by the same method is $785.36 \mathrm{~kg} / \mathrm{m}^{3}$ and the coefficient of variation is $3.69 \%$.

\section{Determination of Poisson's Ratio of Stems}

At each time, a stem with a diameter of about $7 \mathrm{~mm}$ in the middle section of a sweet potato seedling at the mature stage was made into a sample with a length of $20 \mathrm{~mm}$ (Fig. 2a). The sample was sent to a compression test on a WDW-5E microcomputer controlled universal testing machine (Fig. 2b). The compressive stress- strain curve of each sample was acquired at the loading speed of 5 $\mathrm{mm} / \mathrm{min}$ and each test was repeated 10 times. The shear modulus of the sweet potato stem calculated at the mature stage is $6 \mathrm{MPa}$, the elastic modulus is $15.34 \mathrm{MPa}$, Poisson's ratio is 0.28 and the coefficients of variation are 7. $45,9.32$ and $8.77 \%$ respectively.

Table 1: Composition statistics of broken sweet potato seedlings

\begin{tabular}{lllll}
\hline Item stems & Broken leaves & Finely shredded leaves & Long stems & Short \\
\hline Mass percentage\% & 20.32 & 18.10 & 38.24 & 23.34 \\
\hline
\end{tabular}




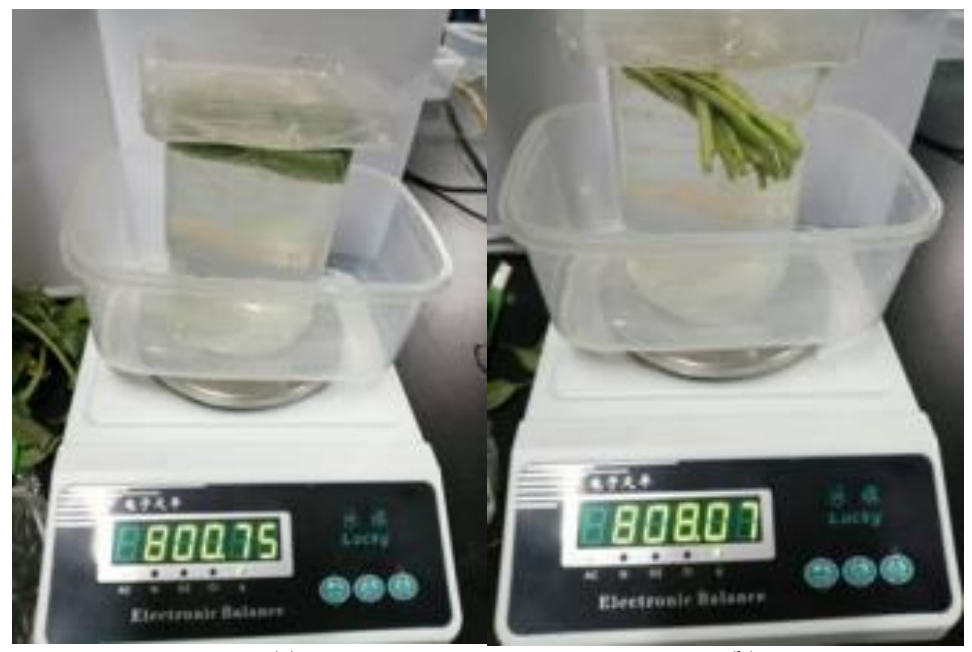

(a)

(b)

Fig. 1: Measuring density with overflow equal volume method; (a) Measure blade density (b) Measure stem density

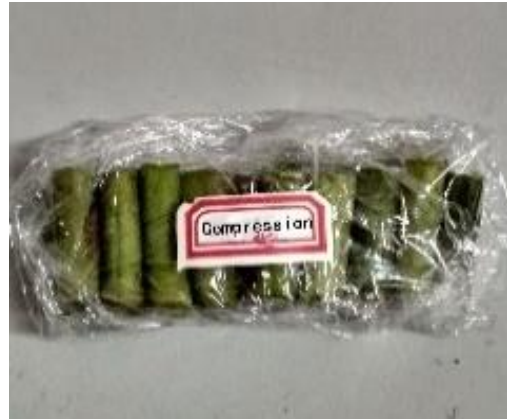

(a)

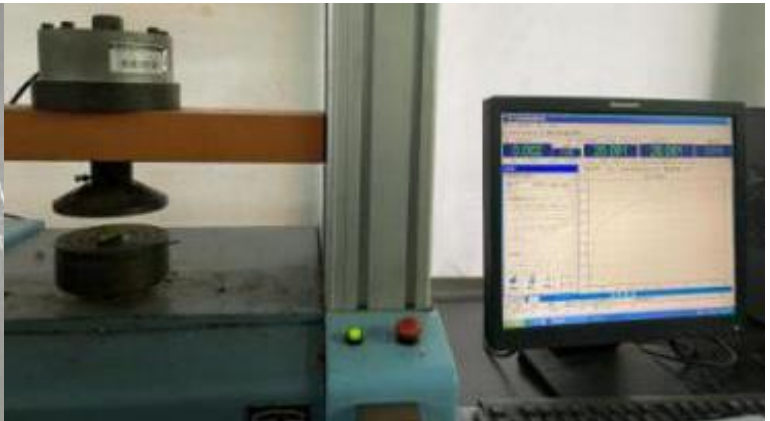

(b)

Fig. 2: Compression test of sweet potato stem; (a) Compressed sample (b) Compression test

Determination of Contact Parameters of Crushed Sweet Potato Seedlings

\section{Collision Recovery Coefficient}

The length-to-diameter ratio of sweet potato stems is large. If free fall collision test is used to measure the collision recovery coefficient, vertical rebound does not easily occur, which seriously affects the measuring accuracy. Hence, the stem-stem/leaf/45 steel collision recovery coefficient was measured by the inclined plate collision method (Huang et al., 2014) and the measurement principle is shown in Fig. 3.

At each time, a stem sample makes a free-fall motion from height $h_{0}$ and after colliding with the collision material (45 steel, leaf, or stem) installed on the collision slope ( $v_{n}$-instantaneous velocity after particle collision), it makes a parabolic motion and falls on the receiving plate. When the relative height between the collision point $o$ and the receiving plate is $h_{1}$ (or $h_{2}$ ), the measured horizontal displacement of the stem is $s_{1}$ (or $s_{2}$ ). The backward movement only has $x$-direction displacement. At this time, the coefficient $e$ of restitution between the stem and the inclined plate is calculated as Eq. (1):

$$
e=\frac{\sqrt{\left(v_{x}^{2}+v_{y}^{2}\right)} \cdot \cos \left[45^{\circ}+\arctan \left(\frac{v_{y}}{v_{x}}\right)\right]}{v_{0} \cdot \sin 45^{\circ}}
$$

where, $v_{0}$ - instantaneous velocity before particle collision, $\mathrm{mm} / \mathrm{s} ; \quad v_{x}$ and $v_{y^{-}}$horizontal and vertical velocity components after particle collision, respectively, $\mathrm{mm} / \mathrm{s}$.

The $v_{0}, v_{x}$ and $v_{y}$ in Eq. (1) are calculated by Eq. (2) and (3):

$v_{0}=\sqrt{2 g h_{0}}$

$\left\{\begin{array}{l}v_{x}=\sqrt{\frac{g s_{1} s_{2}\left(s_{1}-s_{2}\right)}{2\left(h_{1} s_{2}-h_{2} s_{1}\right)}} \\ v_{y}=\frac{h_{1} v_{x}}{s_{1}}-\frac{g s_{1}}{2 v_{x}}\end{array}\right.$ 
A self-made collision coefficient measuring device is shown in Fig. 4. In the measurement of stem-stem recovery coefficient, the tested stem is prone to rotation after colliding with the stem stuck on the collision slope. As a result, displacement occurs in both the $x$ and $y$ directions of the splice plate. This fact is inconsistent with the calculation assumption that the stem has only $x$ direction displacement. Therefore, a 50-mm-wide layer of glue is applied to the splice plate to "capture" the stem. The stem reduces collision and rebound.

when the stem falls outside the range of the red line on the splicing plate, it is an invalid test and the drop point distribution of the sample is shown in Fig. 4b. Totally 50 stems were selected for measurement, 25 in one group and the height of the splicing plate was changed for two tests. The average value of $x$-direction displacement was recorded in each group and the recovery coefficient was calculated by Eq. (1)-(3). The measurement and calculation determine that the recovery coefficients of stem-stem, stem-leaf and stem-steel plate collision are $0.32,0.28$ and 0.44 , respectively and the coefficients of variation are $6.33,8.36$ and $9.03 \%$ respectively.

\section{Static Friction Coefficient}

The static friction coefficients of stem-stem, stem-leaf and stem-45 steel were measured by the inclined surface sliding method (Fangyuan et al., 2018). The self-made static friction coefficient measuring instrument mainly consists of a lifting plate and a digital display angle measuring instrument (Fig. 5). Sweet potato stems with similar diameters were pasted on the lifting plate to measure the stem-stem static friction coefficient. During measurement, the lifting plate was slowly lifted until it stopped when the stem slided on the inclined surface. Then the inclination angle of the inclined plate on the digital angle measuring instrument installed on one side was read. The static friction coefficient, $\mu$, is calculated as Eq. (4):

$\mu=\tan \alpha$

where, $a$ - inclination angle of the inclined plate $\left(^{\circ}\right)$.

The measured static friction coefficient between stemstem ranges from 0.2 to 0.8 . Clean and tidy sweet potato leaves were pasted on the lifting plate. The static friction coefficients between stem-leaf and between leaf-leaf range from 0.3 to 0.6 and from 0.3 to 0.8 respectively. The static friction coefficients between the stem or leaf and the 45 steel measured by the same method range from 0.3 to 0.8 and 0.3 to 0.7 , respectively.

\section{Pile Angle of Crushed Sweet Potato Seedlings}

The pile-up angle of broken seedling particles was determined by the cylinder lifting method. The broken seedlings harvested by the sweet potato seedling recovery machine (to remove impurities) were collected as samples. According to the test requirements of the cylinder lifting method (Jia et al., 2014), a steel cylinder with an inner diameter of $160 \mathrm{~mm}$ and a height of $480 \mathrm{~mm}$ was selected and the steel cylinder filled with crushed seedlings was lifted upward at a speed of $0.05 \mathrm{~m} / \mathrm{s}$ using a CNC milling machine. A pile of crushed seedling particles was formed on the horizontally-fixed bottom plate (Fig. 6). The experiment was repeated 5 times and the average accumulation angle of the crushed seedlings was measured to be $40.12^{\circ}$ and the coefficient of variation was $2.36 \%$.

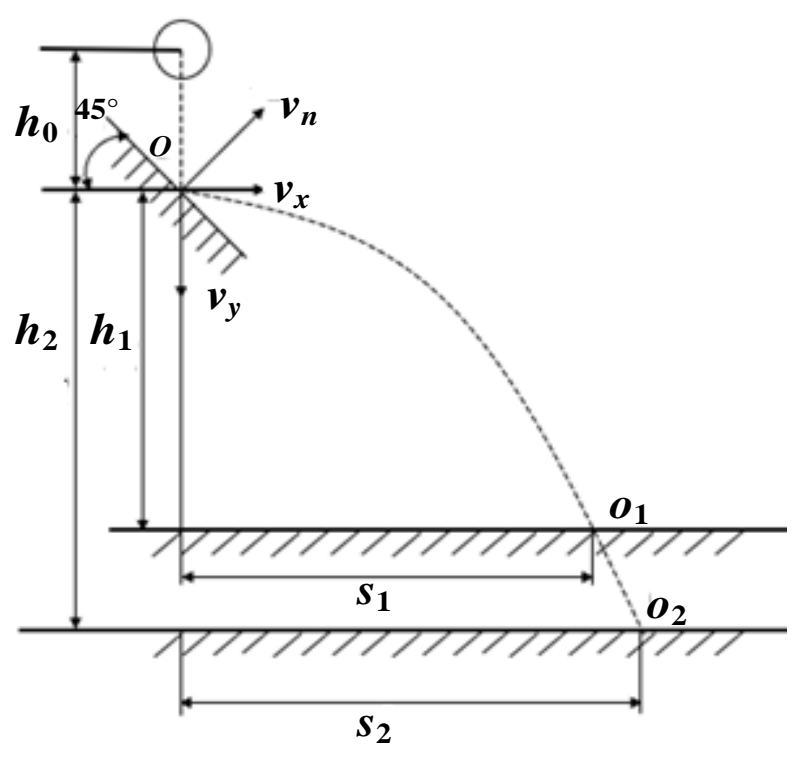

Fig. 3: Principle of measurement 


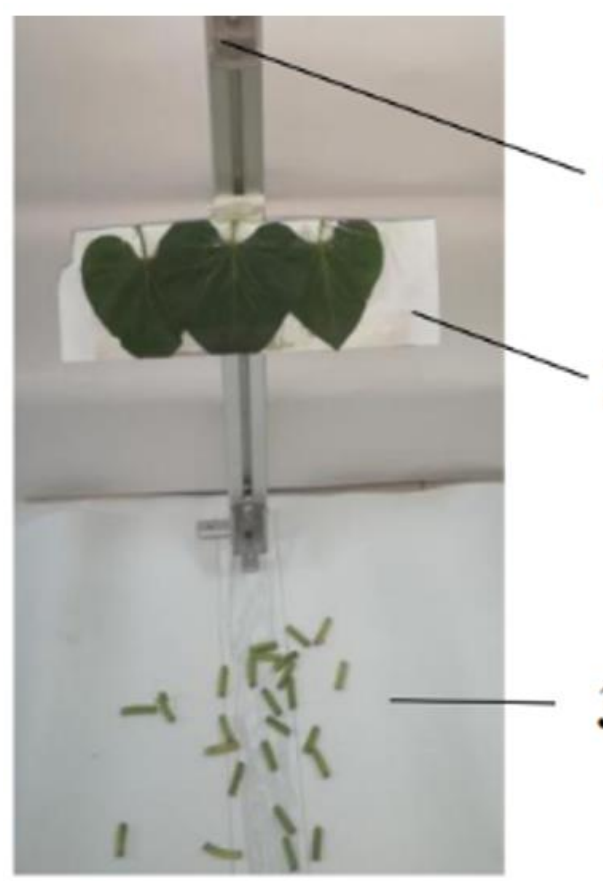

(a)
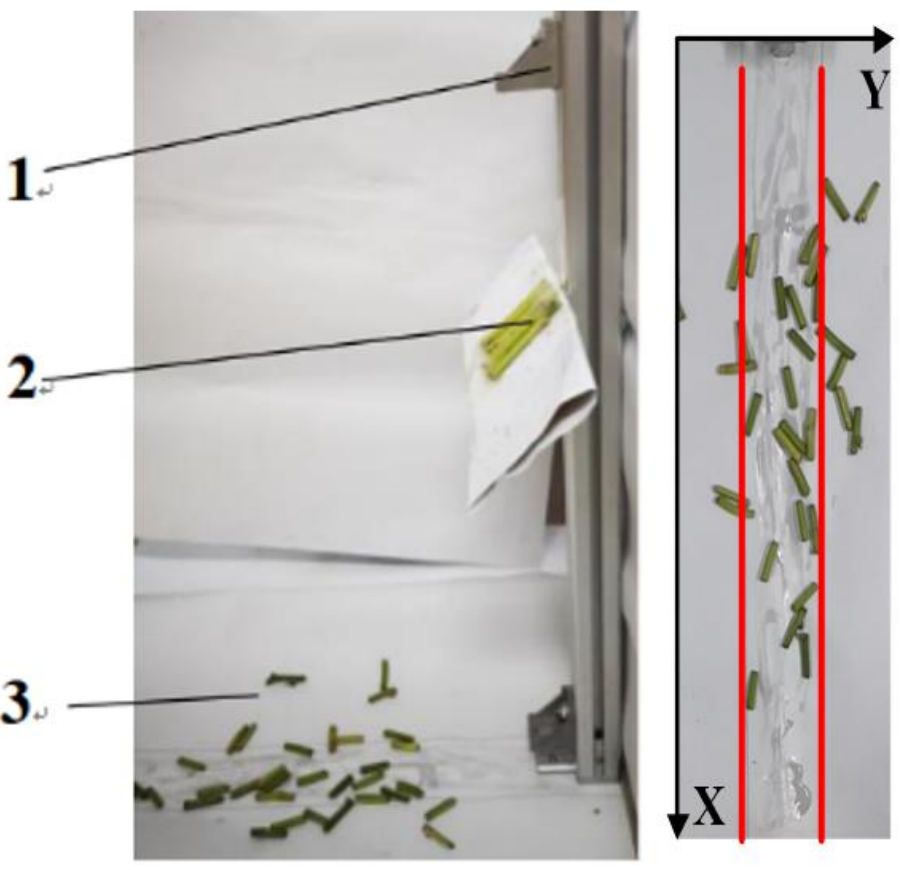

(b)

Fig. 4: Collision recovery coefficient determination 1 feeding point, 2 collision plate, 3 material receiving plate; (a) Inclined plate collision test (b) Distribution of falling points of stems

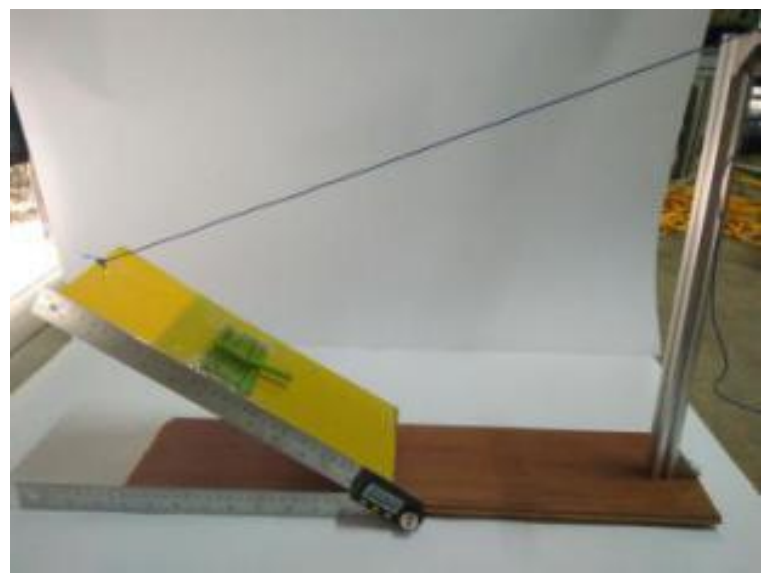

Fig. 5: Static friction coefficient measuring instrument

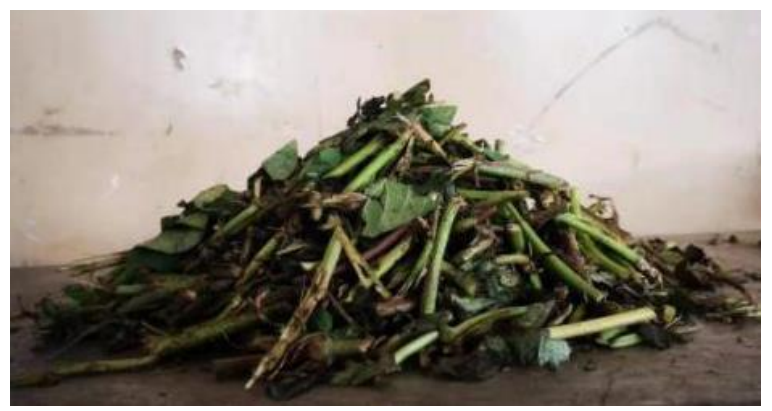

Fig. 6: Heap of broken sweet potato seedlings

\section{Establishment of DEM of Broken Seedlings and Calibration of Main Parameters}

\section{Model of Broken Sweet Potato Seedlings}

To make the broken sweet potato seedling model structurally close to the real broken sweet potato seedling, the geometric model of each component of the broken seedling drawn by SolidWorks was imported into EDEM. Then spherical particles were quickly filled to obtain 4 types of particles, including long-diameter stems (length $30 \mathrm{~mm}$, diameter $7 \mathrm{~mm}$ ), short-diameter stems (length 15 $\mathrm{mm}$, diameter $5 \mathrm{~mm}$ ), broken leaves (area $2.4 \mathrm{~cm}^{2}$ ) and finely-broken leaves (area $1.5 \mathrm{~cm}^{2}$ ) (Fig. 7).

\section{Simulation of Accumulation Angle of Crushed Sweet Potato Seedlings}

In EDEM 2018, a virtual cylinder with an inner diameter of $160 \mathrm{~mm}$ and a height of $480 \mathrm{~mm}$ was established as a pellet factory. Four types of pellets were set in the pellet factory. The pellet factory type was set to be a dynamic factory. According to the actual proportion of crushed seedlings, the generation speeds of long-diameter rod, short-diameter rod, broken leaf and fine broken-leaf were set as 0.33, 0.29, 0.62 and $0.38 \mathrm{~kg} / \mathrm{s}$, respectively and the generation time was $7 \mathrm{~s}$. The contact model between particles was a Hertz-Minglin (no-slip) model. After particles of crushed seedlings were formed, the lifting speed of the cylinder was set at $0.05 \mathrm{~m} / \mathrm{s}$. After the particles were stationary on the substrate, a pile of crushed seedlings was formed (Fig. 8). 


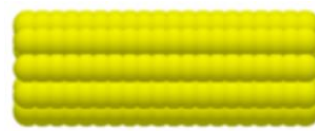

(a)

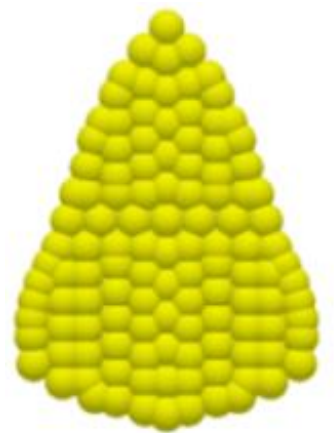

(c)

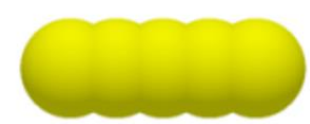

(b)

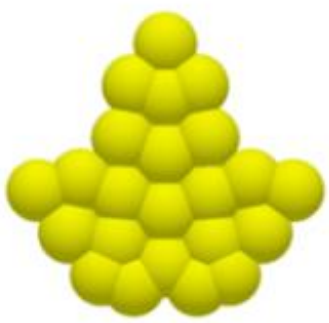

(d)

Fig. 7: Discrete element model of broken sweet potato seedlings; (a) Long stem (b) Short stem (c) Broken blade (d) Finely crushed blade
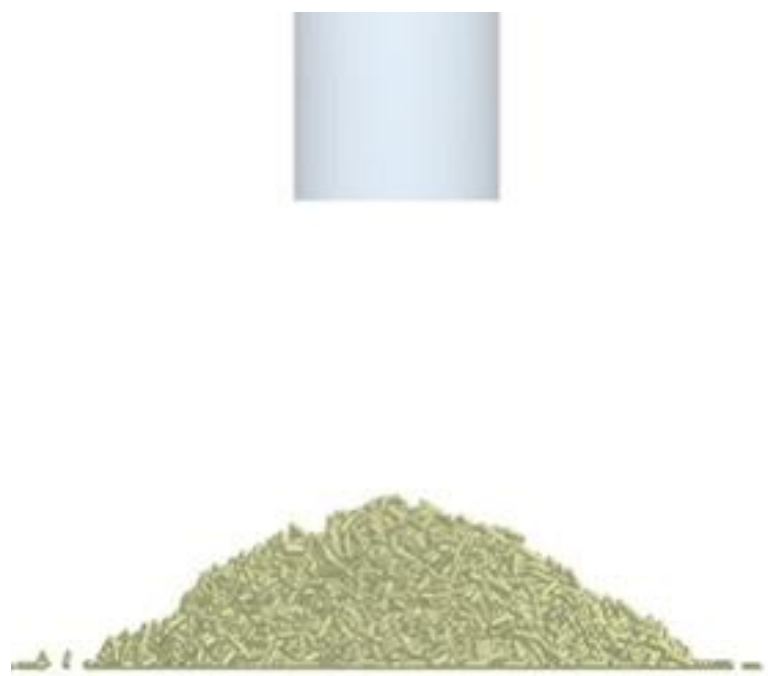

Fig. 8: Schematic diagram of movement path of end point of the knife

Table 2: Test parameters of Plackett-Burman

\begin{tabular}{lrr}
\hline Simulation parameters of sweet potatoes & Level & \\
\hline & -1.00 & 1.0 \\
Poisson's ratio of leaves $x_{1}$ & 0.20 & 0.5 \\
Shear modulus of leaves $x_{2} / \mathrm{MPa}$ & 6.00 & 500.0 \\
Static friction coefficient of stem-stem $x_{3}$ & 0.30 & 0.6 \\
Static friction coefficient of stem-leaf $x_{4}$ & 0.20 & 0.8 \\
Static friction coefficient of stem-45 steel $x_{5}$ & 0.30 & 0.8 \\
Static friction coefficient of leaf-leaf $x_{6}$ & 0.30 & 0.8 \\
Static friction coefficient of leaf-45 steel $x_{7}$ & 0.30 & 0.7 \\
Rolling friction coefficient of stem-stem $x_{8}$ & 0.05 & 0.3 \\
Rolling friction coefficient of stem-leaf $x_{9}$ & 0.00 & 0.3 \\
Rolling friction coefficient of stem-45 steel $x_{10}$ & 0.00 & 0.3 \\
Rolling friction coefficient of leaf-leaf $x_{11}$ & 0.00 & 0.3 \\
Rolling friction coefficient of leaf-45 steel $x_{12}$ & 0.00 & 0.3 \\
Collision recovery coefficient of leaf-leaf $x_{13}$ & 0.10 & 0.5 \\
Impact recovery coefficient of leaf- 45 steel $x_{14}$ & 0.10 & 0.5 \\
\hline
\end{tabular}

\section{Calibration Test of Parameters}

\section{Screening of Influencing Parameters of Particle Stacking Angle of Broken Sweet Potato seedlings}

Many parameters are required to simulate the pile-up angle of the broken seedlings. The stem density, leaf density, shear modulus of stems and Poisson's ratio are $998.91 \mathrm{~kg} / \mathrm{m}^{3}$, $885.36 \mathrm{~kg} / \mathrm{m}^{3}, 6 \mathrm{MPa}$ and 0.28 respectively. The coefficients of collision recovery in stem-stem, stem-leaf and stem-steel plate are $0.32,0.28$ and 0.44 respectively based on the measured values. The shear modulus, Poisson's ratio and density of 45 steels are taken as 0.30 and $7850 \mathrm{~kg} / \mathrm{m}^{3}$. The coefficient of static friction between the grains of crushed seedlings was determined by the test value to determine the parameter ranges. The 14 parameters such as sweet potato leaf shear modulus, Poisson's ratio, rolling friction coefficient between crushed seedling particles and leaf-leaf/45 steel recovery coefficient cannot be tested easily. The value ranges were determined as reported (Lenaerts et al., 2014; Liao et al., 2020). PlackettBurman test design was carried out on Design-Expert 8.0.6 to immediately screen out the parameter combinations that significantly impact the test results. The minimum and maximum values of the 14 parameters are coded as -1 and +1 levels respectively (Table 2 ).

In the Plackett-Burman test, the middle value of the high and low levels was taken as level 0 and a center point test was set up. Totally 21 tests were performed. The test design and results are shown in Table 3 . The variance and significance analysis of the test results are shown in Table 4. Clearly, the static friction coefficient of stem-stem $x_{3}$, the static friction coefficient of stem-steel $x_{5}$, the rolling friction coefficient of stem-stem $x_{8}$ and the rolling friction coefficient of stem-leaf $x_{9}$ all significantly affect the stacking angle. Therefore, in the 
subsequent steepest climb test and Box-Behnken test, only these 4 significant parameters were considered and the other 10 insignificant factors were taken at the intermediate levels. The values of $x_{1}, x_{2}, x_{4}, x_{6}, x_{7}, x_{10}$, $x_{11}, x_{12}, x_{13}$ and $x_{14}$ are $0.35,253,0.5,0.55,0.5,0.15$, $0.15,0.15,0.3,0.3$ respectively.

\section{Steepest Climb Test}

Since the accumulation angle of broken sweet potato seedling particles is enlarged with the increase of 4 significant parameters, 6 sets of steepest climbing experiments were designed and the values of the 4 parameters increased uniformly. The experimental design and results are shown in Table 5. With the gradual increase of the 4 test parameters, the relative error between the simulation and physical test of accumulation angle first decreases and then increases. The relative error of the accumulation angle is the smallest in test No. 3, so the optimal parameter is near test No. 3 .

\section{Box-Behnken Test and Analysis of Significant Contact Parameters}

In the steepest climbing test, the 4 significance parameters in test No. 3 were taken as the intermediate level (0) and the corresponding parameters in tests No. 2 and No. 4 were taken as the low level (-1) and the high level (+1) respectively. The values of the other 10 parameters are the same as the steepest climbing test. Response surface test was designed on Design-Expert 8.0.6 to obtain the optimal values of the 4 significant contact parameters. The Box-Behnken experiment design and results are shown in Table 6.

The test results in Table 6 were fitted on Design-Expert 8.0.6 and the quadratic regression full model of the broken sweet potato seedling particle packing angle and the 4 significant contact parameters was expressed as Eq. (5):

$$
\begin{aligned}
& \theta=39.58+0.96 x_{3}+1.06 x_{5}+0.96 x_{8}+0.98 x_{9} \\
& +0.14 x_{3} x_{5}+0.11 x_{3} x_{8}+0.38 x_{3} x_{9}+0.40 x_{5} x_{8} \\
& +0.36 x_{5} x_{9}+0.24 x_{8} x_{9}-0.27 x_{3}^{2}-0.44 x_{5}^{2} \\
& -0.41 x_{8}^{2}-0.36 x_{9}^{2}
\end{aligned}
$$

The variance analysis of the model test results is shown in Table 7. The fitted model $\mathrm{P}<0.0001$ and the coefficient of determination $\mathrm{R}^{2}=0.9938$ close to 1 indicate the regression model is extremely significant and can predict the target accumulation angle. The lack of fit term $\mathrm{P}=0.181>0.05$ and the low coefficient of variation $\mathrm{CV}=$ $0.39 \%$ indicate the regression equation has a good fit.

\section{Verification and Determination of Simulation Optimal Parameter Combination}

With the optimization module in Design-Expert 8.0.6, Eq. (7) was optimized with the tested accumulation angle of $40.12^{\circ}$ as the target value. The values of $x_{3}, x_{5}, x_{8}$ and $x_{9}$ are $0.41,0.53,0.17$ and 0.13 , respectively. The result is the best when the remaining non-significant parameters are taken at the middle values. To test the accuracy of the optimal parameter combination, the above parameter values were used to carry out 5 particle accumulation simulation tests. The average value of particle accumulation angle of crushed sweet potato seedlings was measured to be $40.51^{\circ}$ and the relative error between the accumulation angle $40.12^{\circ}$ and the actual physical test was $0.972 \%$, indicating the calibrated

\begin{tabular}{|c|c|c|c|c|c|c|c|c|c|c|c|c|c|c|c|}
\hline Serial number & $x_{1}$ & $x_{2}$ & $x_{3}$ & $x_{4}$ & $x_{5}$ & $x_{6}$ & $x_{7}$ & $x_{8}$ & $x_{9}$ & $x_{10}$ & $x_{11}$ & $x_{12}$ & $x_{13}$ & $x_{14}$ & Numerical \\
\hline 1 & 1 & -1 & 1 & 1 & -1 & -1 & 1 & 1 & 1 & 1 & -1 & 1 & -1 & 1 & 41.55 \\
\hline 2 & -1 & 1 & -1 & -1 & -1 & -1 & 1 & 1 & -1 & 1 & 1 & -1 & -1 & 1 & 34.51 \\
\hline 3 & 1 & 1 & -1 & 1 & 1 & -1 & -1 & 1 & 1 & 1 & 1 & -1 & 1 & -1 & 42.35 \\
\hline 4 & -1 & 1 & -1 & 1 & -1 & -1 & -1 & -1 & 1 & 1 & -1 & 1 & 1 & -1 & 32.22 \\
\hline 5 & 1 & 1 & -1 & -1 & 1 & 1 & 1 & 1 & -1 & 1 & -1 & 1 & -1 & -1 & 36.82 \\
\hline 6 & 1 & -1 & 1 & -1 & -1 & -1 & -1 & 1 & 1 & -1 & 1 & 1 & -1 & -1 & 41.24 \\
\hline 7 & -1 & 1 & 1 & 1 & 1 & -1 & 1 & -1 & 1 & -1 & -1 & -1 & -1 & 1 & 42.49 \\
\hline 8 & -1 & -1 & 1 & 1 & -1 & 1 & 1 & -1 & -1 & 1 & 1 & 1 & 1 & -1 & 31.83 \\
\hline 9 & -1 & 1 & 1 & -1 & -1 & 1 & 1 & 1 & 1 & -1 & 1 & -1 & 1 & -1 & 41.46 \\
\hline 10 & -1 & -1 & 1 & 1 & 1 & 1 & -1 & 1 & -1 & 1 & -1 & -1 & -1 & -1 & 43.05 \\
\hline 11 & 1 & -1 & -1 & -1 & -1 & 1 & 1 & -1 & 1 & 1 & -1 & -1 & 1 & 1 & 31.22 \\
\hline 12 & 1 & 1 & 1 & 1 & -1 & 1 & -1 & 1 & -1 & -1 & -1 & -1 & 1 & 1 & 39.16 \\
\hline 13 & 1 & -1 & 1 & -1 & 1 & -1 & -1 & -1 & -1 & 1 & 1 & -1 & 1 & 1 & 38.35 \\
\hline 14 & 1 & 1 & -1 & 1 & -1 & 1 & -1 & -1 & -1 & -1 & 1 & 1 & -1 & 1 & 30.55 \\
\hline 16 & 1 & 1 & 1 & -1 & 1 & -1 & 1 & -1 & -1 & -1 & -1 & 1 & 1 & -1 & 38.91 \\
\hline 17 & -1 & -1 & -1 & -1 & 1 & 1 & -1 & 1 & 1 & -1 & -1 & 1 & 1 & 1 & 41.76 \\
\hline 18 & -1 & -1 & -1 & -1 & -1 & -1 & -1 & -1 & -1 & -1 & -1 & -1 & -1 & -1 & 26.21 \\
\hline 19 & 1 & -1 & -1 & 1 & 1 & 1 & 1 & -1 & 1 & -1 & 1 & -1 & -1 & -1 & 37.42 \\
\hline 20 & -1 & -1 & -1 & 1 & 1 & -1 & 1 & 1 & -1 & -1 & 1 & 1 & 1 & 1 & 36.62 \\
\hline 21 & 0 & 0 & 0 & 0 & 0 & 0 & 0 & 0 & 0 & 0 & 0 & 0 & 0 & 0 & 41.04 \\
\hline
\end{tabular}
granular parameters of crushed seedlings are feasible. The values of each parameter are shown in Table 8.

Table 3: Plackett-Burman experiment design scheme and response value 
Guizhi Mu et al./ American Journal of Biochemistry and Biotechnology 2021, 17 (2): 256.266 DOI: 10.3844/ajbbsp.2021.256.266

Table 4: Variance and significance analysis of Plackett-Burman test

\begin{tabular}{lcccl}
\hline Parameter & The sum of square & Variance & F-value & P-value \\
\hline$x_{1}$ & 1.210 & 1 & 23.560 & 0.3916 \\
$x_{2}$ & 6.880 & 1 & 0.880 & 0.0753 \\
$x_{3}$ & 129.390 & 1 & 5.010 & $0.0002 * *$ \\
$x_{4}$ & 0.910 & 1 & 94.300 & 0.4521 \\
$x_{5}$ & 126.660 & 1 & 0.660 & $0.0002 * *$ \\
$x_{6}$ & 0.086 & 1 & 92.310 & 0.8125 \\
$x_{7}$ & 1.040 & 1 & 0.063 & 0.4248 \\
$x_{8}$ & 109.560 & 1 & 0.750 & $0.0003 * *$ \\
$x_{9}$ & 73.000 & 1 & 79.850 & $0.0008 * *$ \\
$x_{10}$ & 0.100 & 1 & 53.210 & 0.7958 \\
$x_{11}$ & 0.590 & 1 & 0.075 & 0.5415 \\
$x_{12}$ & 0.250 & 1 & 0.430 & 0.688 \\
$x_{13}$ & 0.310 & 1 & 0.180 & 0.6571 \\
$x_{14}$ & 2.600 & 1 & 0.220 & 0.2271 \\
\hline
\end{tabular}

Note: $\mathrm{P}<0.01$ (highly significant, $* *), \mathrm{P}<0.05$ (significant, ${ }^{*}$ )

Table 5: Experimental results of the steepest ascent test

\begin{tabular}{lllllll}
\hline Parameter & $x_{3}$ & $x_{5}$ & $x_{8}$ & $x_{9}$ & Stacking angle $\theta /\left(^{\circ}\right)$ & Relative error/\% \\
\hline 1 & 0.30 & 0.30 & 0.05 & 0.00 & 30.35 & $24.35 \%$ \\
2 & 0.36 & 0.40 & 0.10 & 0.06 & 36.69 & $8.55 \%$ \\
3 & 0.42 & 0.50 & 0.15 & 0.12 & 39.55 & $1.42 \%$ \\
4 & 0.48 & 0.60 & 0.20 & 0.18 & 41.56 & $3.59 \%$ \\
5 & 0.54 & 0.70 & 0.25 & 0.24 & 44.33 & $10.49 \%$ \\
6 & 0.60 & 0.80 & 0.30 & 0.30 & 48.03 & $19.71 \%$ \\
\hline
\end{tabular}

Table 6: Box-Behnken experimental design and results of significant parameters

\begin{tabular}{|c|c|c|c|c|c|}
\hline Serial number & $x_{3}$ & $x_{5}$ & $x_{8}$ & $x_{9}$ & Numerical \\
\hline 1 & 1 & 0 & 1 & 0 & 41.06 \\
\hline 2 & 0 & 0 & 0 & 0 & 39.41 \\
\hline 3 & 0 & 0 & 0 & 0 & 39.63 \\
\hline 4 & 1 & 0 & 0 & -1 & 38.65 \\
\hline 5 & 0 & 1 & 0 & 1 & 41.06 \\
\hline 6 & 1 & 1 & 0 & 0 & 40.87 \\
\hline 7 & -1 & 0 & 0 & -1 & 37.53 \\
\hline 8 & 0 & 0 & -1 & 1 & 38.69 \\
\hline 9 & 0 & 0 & 1 & 1 & 41.03 \\
\hline 10 & 0 & 0 & -1 & -1 & 36.98 \\
\hline 11 & 0 & 0 & 0 & 0 & 39.67 \\
\hline 12 & -1 & 1 & 0 & 0 & 38.87 \\
\hline 13 & 0 & -1 & -1 & 0 & 37.22 \\
\hline 14 & 0 & 1 & -1 & 0 & 38.57 \\
\hline 15 & 1 & 0 & -1 & 0 & 38.80 \\
\hline 16 & 0 & 1 & 1 & 0 & 41.21 \\
\hline 17 & 0 & -1 & 0 & 1 & 38.23 \\
\hline 18 & -1 & -1 & 0 & 0 & 37.06 \\
\hline 19 & 1 & 0 & 0 & 1 & 41.33 \\
\hline 20 & 0 & 0 & 1 & -1 & 38.37 \\
\hline 21 & -1 & 0 & 1 & 0 & 38.70 \\
\hline 22 & -1 & 0 & 0 & 1 & 38.67 \\
\hline 23 & -1 & 0 & -1 & 0 & 36.89 \\
\hline 24 & 0 & -1 & 1 & 0 & 38.26 \\
\hline 25 & 0 & -1 & 0 & -1 & 37.15 \\
\hline 26 & 0 & 0 & 0 & 0 & 39.63 \\
\hline 27 & 0 & 1 & 0 & -1 & 38.54 \\
\hline 28 & 0 & 0 & 0 & 0 & 39.57 \\
\hline 29 & 1 & -1 & 0 & 0 & 38.51 \\
\hline
\end{tabular}


Table 7: Variation analysis of Box-Behnken design quadratic model

\begin{tabular}{lcccc}
\hline Parameter & Sum of square & Variance & F-value & P-value \\
\hline Model & 51.510 & 14.00 & 160.99 & $<0.0001^{* *}$ \\
$x_{3}$ & 11.020 & 1.00 & 482.25 & $<0.0001^{* *}$ \\
$x_{5}$ & 13.420 & 1.00 & 587.22 & $<0.0001^{* *}$ \\
$x_{8}$ & 10.980 & 1.00 & 480.58 & $<0.0001^{* *}$ \\
$x_{9}$ & 11.580 & 1.00 & 506.88 & $<0.0001^{* *}$ \\
$x_{3} x_{5}$ & 0.076 & 1.00 & 3.31 & 0.0903 \\
$x_{3} x_{8}$ & 0.051 & 1.00 & 2.22 & 0.1588 \\
$x_{3} x_{9}$ & 0.590 & 1.00 & 25.94 & 0.0002 \\
$x_{5} x_{8}$ & 0.640 & 1.00 & 28.01 & 0.0001 \\
$x_{5} x_{9}$ & 0.520 & 1.00 & 22.68 & 0.0003 \\
$x_{8} x_{9}$ & 0.230 & 1.00 & 9.87 & 0.0072 \\
$x_{3}^{2}$ & 0.460 & 1.00 & 20.27 & 0.0005 \\
$x_{5}{ }^{2}$ & 1.260 & 1.00 & 55.20 & $<0.0001^{* *}$ \\
$x_{8}^{2}$ & 1.100 & 1.00 & 48.24 & $<0.0001^{* *}$ \\
$x_{8}{ }^{2}$ & 0.820 & 1.00 & 35.97 & $<0.0001^{* *}$ \\
residual & 0.320 & 14.00 & 2.64 & 0.181 \\
Missing item & 0.280 & 10.00 & & \\
Pure error & 0.042 & 4.00 & & \\
Sum & 51.830 & 28.00 & &
\end{tabular}

Table 8: Discrete element simulation parameter values

\begin{tabular}{lr}
\hline Simulation parameters of sweet potatoes & \multicolumn{1}{c}{ Level } \\
\hline Stem density $/ \mathrm{kg} / \mathrm{m}^{3}$ & 998.91 \\
Leaf density $/ \mathrm{kg} / \mathrm{m}^{3}$ & 885.36 \\
45 steel density $/ \mathrm{kg} / \mathrm{m}^{3}$ & 7850.00 \\
Poisson's ratio of stem & 0.28 \\
Poisson's ratio of leaf & 0.35 \\
45 steel Poisson's ratio & 0.30 \\
Shear modulus of stem & 6.00 \\
Shear modulus of leaf & 253.00 \\
Shear modulus of 45 steel & 70000.00 \\
Collision recovery coefficient of stem-stem & 0.32 \\
Collision recovery coefficient of stem-leaf & 0.28 \\
Impact recovery coefficient of stem- 45 steel & 0.44 \\
Collision recovery coefficient of leaf-leaf & 0.30 \\
Impact recovery coefficient of leaf- 45 steel & 0.30 \\
Static friction coefficient of stem-stem & 0.41 \\
Static friction coefficient of stem-leaf & 0.50 \\
Static friction coefficient of stem- 45 steel & 0.53 \\
Static friction coefficient of leaf-leaf & 0.55 \\
Static friction coefficient of leaf- 45 steel & 0.50 \\
Rolling friction coefficient of stem-stem & 0.17 \\
Rolling friction coefficient of stem- leaf & 0.13 \\
Rolling friction coefficient of stem- 45 steel & 0.15 \\
Rolling friction coefficient of leaf- leaf & 0.15 \\
Rolling friction coefficient of leaf- 45 steel & 0.15 \\
\hline
\end{tabular}

\section{Conclusion}

The stem density of sweet potato measured by the overflow equal volume method is $987.91 \mathrm{~kg} / \mathrm{m}^{3}$ and the coefficient of variation is $3.34 \%$. The leaf density is $785.36 \mathrm{~kg} / \mathrm{m}^{3}$ and the coefficient of variation is $3.69 \%$. The coefficients of recovery from the collision between stem-stem, stem-leaf and stem-steel plate are 0.32, 0.28 and 0.44 , respectively and the coefficients of variation are $6.33,8.36$ and $9.03 \%$, respectively. The elastic modulus, shear modulus and Poisson's ratio of the mature sweet potato seedling stems measured by the compression test are $15.34,6 \mathrm{MPa}$ and 0.28 , respectively and the coefficients of variation are 7.45, 9.32 and $8.77 \%$, respectively. Through cylinder lifting method particle accumulation test, the average accumulation angle of broken sweet potato seedlings is $40.51^{\circ}$ and the coefficient of variation is $2.36 \%$.

Plackett-Burman simulation shows the static friction coefficient and rolling friction coefficient significantly affect the accumulation angle. Box-Behnken test was performed on the significant parameters on the stacking angle of crushed sweet potato seedlings and a secondorder regression model between stacking angle and significance parameters was established. The optimization was performed with the goal of $40.12^{\circ}$ and the optimal solution was obtained. The stem-stem, stem-steel static friction coefficients and the stem-stem, stem-leaf rolling friction coefficients are $0.41,0.53,0.17$ and 0.13 , respectively. With the obtained contact parameters, a simulation test of the particle accumulation of crushed sweet potato seedlings was carried out. The measured average accumulation angle is $38.71^{\circ}$ and the relative error between the simulation result and the measured value is $0.972 \%$, indicating the optimal parameter combination is desirable.

Although the accumulation angle of broken sweet potato seedling particles is determined by the typical lifting method, the stalk length of the broken sweet potato seedling particles is relatively large and it is difficult to form a continuous flow boundary. The calibration results may be affected by the calibration test and the shape of the particles.

In the future research, more virtual calibration experiments and particle shapes should be selected to further study the calibration of simulation parameters, so as to establish a discrete element simulation parameter database of crushed sweet potato. 


\section{Acknowledgement}

This work was supported by the Foundation of Shandong Province Agricultural Good Seed Project (No.2020LZGC00405-1), Agricultural Equipment Research and Development Innovation Program of Shandong Province (No.2017YF002), Key R\&D Projects in Shandong Province (No.2019GNC106021), Expert Project of Agricultural machinery Post of Potato Innovation Team of Modern Agricultural Industry Technology System of Shandong Province (No.SDAIT-16-10), Shandong Province Key Laboratory of Horticultural Machinery and Equipment Project (No.YYJX-2019-07).

\section{Author Contributions}

Guizhi Mu and Xieteng Qi: Designed and performed the experiments, analyzed the data and prepared the paper.

Wangzhi Zhang and Zhaoqin Lv: Participated to collect the materials related to the experiment.

Tingting Zhang and Shuwen Wang: Designed the experiments and revised the manuscript.

\section{Conflict of Interest}

The authors declare that they have no competing interests. The corresponding author affirms that all of the authors have read and approved the manuscript.

\section{References}

Boac, J. M., Casada, M. E., Maghirang, R. G., \& Harner, J. P. (2009). Material and interaction properties of selected grains and oilseeds for modeling discrete particles. In 2009 Reno, Nevada, June 21-June 24, 2009 (p. 1). American Society of Agricultural and Biological Engineers. https://doi.org/10.13031/2013.32577

Fangyuan, L., Xu, M., Suiyan, T., Lintao, C., Lingtao, Z., \& Pei, A. (2018). Simulative calibration and experiment on main contact parameters of discrete elements for rice bud seeds. Transactions of the Chinese Society for Agricultural Machinery, 49(2), 93-99. https://doi.org/10.5109/1955404

González-Montellano, C., Fuentes, J. M., Ayuga-Téllez, E., \& Ayuga, F. (2012). Determination of the mechanical properties of maize grains and olives required for use in DEM simulations. Journal of Food Engineering, 111(4), 553-562. https://doi.org/10.1016/j.jfoodeng.2012.03.017

Grima, A. P., \& Wypych, P. W. (2011). Development and validation of calibration methods for discrete element modelling. Granular Matter, 13(2), 127-132. https://doi.org/10.1007/s10035-010-0197-4
Guizhi, M., Qingqing, X., \& Guantao, X. (2019). Design and experimental research of knife roller and throwing device for sweet potato vine recycling machine. Transactions of the Chinese Society for Agricultural Machinery, 50(12), 53-62. https://doi.org/10. 6041/j.issn.1000-1298.2019.12.006

Horabik, J., \& Molenda, M. (2016). Parameters and contact models for DEM simulations of agricultural granular materials: A review. Biosystems Engineering, 147, 206-225. https://doi.org/10.1016/j.biosystemseng.2016.02.017

Huang, X., Zha, X., Pan, H., Zong, W., \& Chen, H. (2014). Measurement and analysis of rapeseeds' restitution coefficient in point-to-plate collision model. Transactions of the Chinese Society of Agricultural Engineering, 30(24), 22-29.

https://www.ingentaconnect.com/content/tcsae/tcsae /2014/00000030/00000024/art00003

Jia, F., Han, Y., Liu, Y., Cao, Y., Shi, Y., Yao, L., \& Wang, H. (2014). Simulation prediction method of repose angle for rice particle materials. Transactions of the Chinese Society of Agricultural Engineering, 30(11), 254-260.

https://www.ingentaconnect.com/content/tcsae/tcsae/2 014/00000030/00000011/art00031

Junxiao, F., Jia, L., \& Shizhong, L. (2015). Calibration of discrete element parameters of particle in rotary solid state fermenters. Transactions of the Chinese Society for Agricultural Machinery, 46(3), 208-213. https://doi.org/10.6041/j.issn.10001298.2015.03.030

Kakahy, A. N., Ahmad, D., Akhir, M. D., Sulaiman, S., \& Ishak, A. (2014). Effects of rotary mower blade cutting angles on the pulverization of sweet potato vine. Agriculture and Agricultural Science Procedia, 2, 95-101. https://doi.org/10.1016/j.aaspro.2014.11.014

Leblicq, T., Smeets, B., Ramon, H., \& Saeys, W. (2016). A discrete element approach for modelling the compression of crop stems. Computers and Electronics in Agriculture, 123, 80-88. https://doi.org/10.1016/j.compag.2016.02.018

Lee, S., \& Park, J. (2019). Standardized Friction Experiment for Parameter Determination of Discrete Element Method and Its Validation Using Angle of Repose and Hopper Discharge. Multiscale Science and Engineering, 1(3), 247-255. https://doi.org/10.1007/s42493-01900020-610.1007/s42493-019-00020-6

Lenaerts, B., Aertsen, T., Tijskens, E., De Ketelaere, B., Ramon, H., De Baerdemaeker, J., \& Saeys, W. (2014). Simulation of grain-straw separation by discrete element modeling with bendable straw particles. Computers and Electronics in Agriculture, 101, 24-33. https://doi.org/10.1016/j.compag.2013.12.002 
Liao, Y. T., Liao, Q. X., Zhou, Y., Wang, Z. T., Jiang, Y. J., \& Liang, F. (2020). Parameters calibration of discrete element model of fodder rape crop harvest in bolting stage. Transactions of the Chinese Society for Agricultural Machinery, 30, 1-12. https://doi.org/10.13031/aim.202001513

Martin, C. L., Bouvard, D., \& Shima, S. (2003). Study of particle rearrangement during powder compaction by the discrete element method. Journal of the Mechanics and Physics of Solids, 51(4), 667-693. https://doi.org/10.1016/S0022-5096(02)00101110.1016/s0022-5096(02)00101-1

Santos, K. G., Campos, A. V. P., Oliveira, O. S., Ferreira, L. V., Francisquetti, M. C., \& Barrozo, M. A. S. (2015). Dem simulations of dynamic angle of repose of acerola residue: a parametric study using a response surface technique. Blucher Chemical Engineering Proceedings, 1(2), 11326-11333. https://doi.org/10.5151/chemengcobeq2014-0187-26615-184001
Sweijen, T., Hassanizadeh, S. M., Aslannejad, H., \& Leszczynski, S. (2020). The effect of particle shape on porosity of swelling granular materials: Discrete element method and the multi-sphere approximation. Powder Technology, 360, 1295-1304. https://doi.org/10.1016/j.powtec.2019.09.03610.101 6/j.powtec.2019.09.036

Ucgul, M., Fielke, J. M., \& Saunders, C. (2014). Threedimensional discrete element modelling of tillage: Determination of a suitable contact model and parameters for a cohesionless soil. Biosystems Engineering, 121, 105-117.

https://doi.org/10.1016/j.biosystemseng.2014.02.0 0510.1016/j.biosystemseng.2014.02.005

Zhao, D., \& Gao, Z. (2012). Research on the development in the sweet potato stem leaves treatment and harvesting machines at home and abroad. Agricultural Science Technology and Equipment, 216(6), 19-20.

https://doi.org/10.16313/j.cnki.nykjyzb.2012.06.024 